\title{
Modelagem e mapeamento de áreas de perigo de inundação urbana na cidade de Francisco Beltrão (Brasil)
}

\author{
Modeling and mapping of hazard areas to urban floods in \\ Francisco Beltrão (Brazil)
}

\author{
Ariadne Farias, Doutorado em Meio Ambiente e Desenvolvimento, Brasil, ariadnegeo21@gmail.com \\ (1) https://orcid.org/0000-0002-2816-0968 \\ Francisco Mendonça, Departamento de Geografia, Universidade Federal do Paraná, Brasil, \\ chico@ufpr.com.br \\ (1) https://orcid.org/0000-0002-3107-8519
}

\begin{abstract}
Resumo: A intensificação da urbanização-industrialização brasileira, após a década de 1970, gerou uma considerável degradação ambiental no país com expressivos impactos negativos aos ecossistemas e à população urbana. Diante desse cenário, o sistema hídrico é um dos primeiros a evidenciar os sinais da degradação ambiental nas cidades. Na Região Sul do país a ocorrência de eventos hidrometeorológicos extremos tem gerado preocupação nas instituições públicas e privadas, uma vez que as inundações vêm causando, a cada ano, elevados prejuízos à população, à infraestrutura e aos serviços localizados nas áreas de risco. Nesse contexto, o presente artigo apresenta os procedimentos metodológicos utilizados no mapeamento das áreas de perigo natural de inundação, ou seja, daquelas afetadas pelo espraiamento das cheias dos rios e canais urbanos. $O$ objetivo do estudo foi demonstrar a aplicação das técnicas de modelagem hidrológica e dos recursos da cartografia digital ao estudo de caso das inundações registradas na cidade de Francisco Beltrão, localizada no estado do Paraná.
\end{abstract}

Palavras-chave: Inundação urbana; modelagem hidrológica; perigo natural; desastres.

\begin{abstract}
The intensification of Brazilian urbanization-industrialization after the 1970s generated important environmental degradation in the country with significant negative impacts on ecosystems and the urban population. Given this scenario, the urban water system is one of the first to show signs of environmental degradation in cities. In the southern region of the country, the occurrence of hydrometeorological extreme events has caused, year by year, high damages concern in public and private institutions, population, infrastructure and services located in risk areas. In this context, this paper presents the methodological procedures used in the mapping of hazard flooding areas, that is, those affected by rivers and urban canals floods. This study aimed to demonstrate hydrological modeling techniques application and the resources of digital cartography to the case study of the floods recorded in the Francisco Beltrão city, located in the state of Paraná.
\end{abstract}

Keywords: Urban flooding; hydrological modeling; natural hazard; disasters.

\section{Introdução}

No Brasil, a intensificação da urbanização-industrialização após a década de 1970 gerou considerável degradação ambiental, provocando impactos negativos aos ecossistemas e à população urbana. Desmatamento, ocupação de áreas de proteção ambiental, impermeabilização, compactação e erosão do solo, aumento do escoamento das águas superficiais pluviais, acréscimo significativo da poluição 
doméstica e industrial, insuficiente saneamento ambiental, pobreza, etc. são processos e eventos comumente observados nas cidades brasileiras.

O retrato da degradação ambiental demonstra que os problemas socioambientais urbanos vêm se intensificando ao longo do tempo e se tornaram um grande desafio no século XXI. Os efeitos desse processo também atingem o funcionamento dos sistemas de infraestrutura que dão suporte à vida nas cidades. À medida que o processo de urbanização-industrialização se intensifica, gera maior pressão sobre a infraestrutura urbana, muitas vezes, deficitária ou mesmo inexistente. Neste cenário, o sistema hídrico é um dos primeiros a apresentar os sinais da degradação ambiental (Mendonça, 2004, 2004a; Tucci, 2003).

Os impactos da urbanização-industrialização interferem diretamente na dinâmica natural dos rios urbanos e geram problemas, tais como: aumento das vazões máximas; erosão das encostas; aumento da produção de sedimentos e assoreamento dos leitos dos rios e canais; alterações na morfologia fluvial; sobrecarga nos dispositivos de micro e macrodrenagem; comprometimento da qualidade das águas superficiais e subterrâneas, utilizadas para o abastecimento da população; entre outros.

A investigação dos problemas socioambientais relacionados à gestão das águas urbanas é temática de interesse de pesquisadores de diversas áreas do conhecimento, em especial, da Geografia, e desperta, também, a atenção dos gestores públicos. Além disso, a ocorrência de eventos extremos de precipitação registrados na região Sul do Brasil tem gerado preocupação nas instituições públicas e privadas, uma vez que as inundações vêm causando, a cada ano, sérios prejuízos à população, à infraestrutura e aos serviços localizados nas áreas de risco.

Dentre os fenômenos naturais extremos, os eventos hidrológicos correspondem aos maiores índices de desastres registrados nas cidades brasileiras, na maioria dos casos, associados às chuvas intensas (Tucci, 2007; Kobyama et al., 2004; Monteiro, 1991). Essas precipitações podem causar alagamentos e inundações, eventos decorrentes do aumento significativo da vazão de pico, sobrecarga dos sistemas de drenagem e/ou transbordamento do nível dos rios, córregos e canais.

Em face das inúmeras ocorrências de desastres relacionados às inundações, buscam-se metodologias que possam auxiliar na redução dos riscos e das vulnerabilidades socioambientais urbanas. Nesse contexto, o presente artigo apresenta os procedimentos metodológicos utilizados no mapeamento das áreas de perigo natural de inundação, ou seja, daquelas afetadas pelo espraiamento das cheias dos rios e canais urbanos.

O estudo demonstra a aplicação das técnicas de modelagem hidrológica e dos recursos da cartografia digital ao estudo de caso das inundações registradas na cidade de Francisco Beltrão, localizada no estado do Paraná, na região Sul do Brasil (Figura 1). Este texto coloca em evidência a identificação do perigo de inundação 
presente na rede de drenagem da bacia hidrográfica do rio Marrecas, ao qual uma parcela significativa da população urbana de Francisco Beltrão encontra-se exposta.

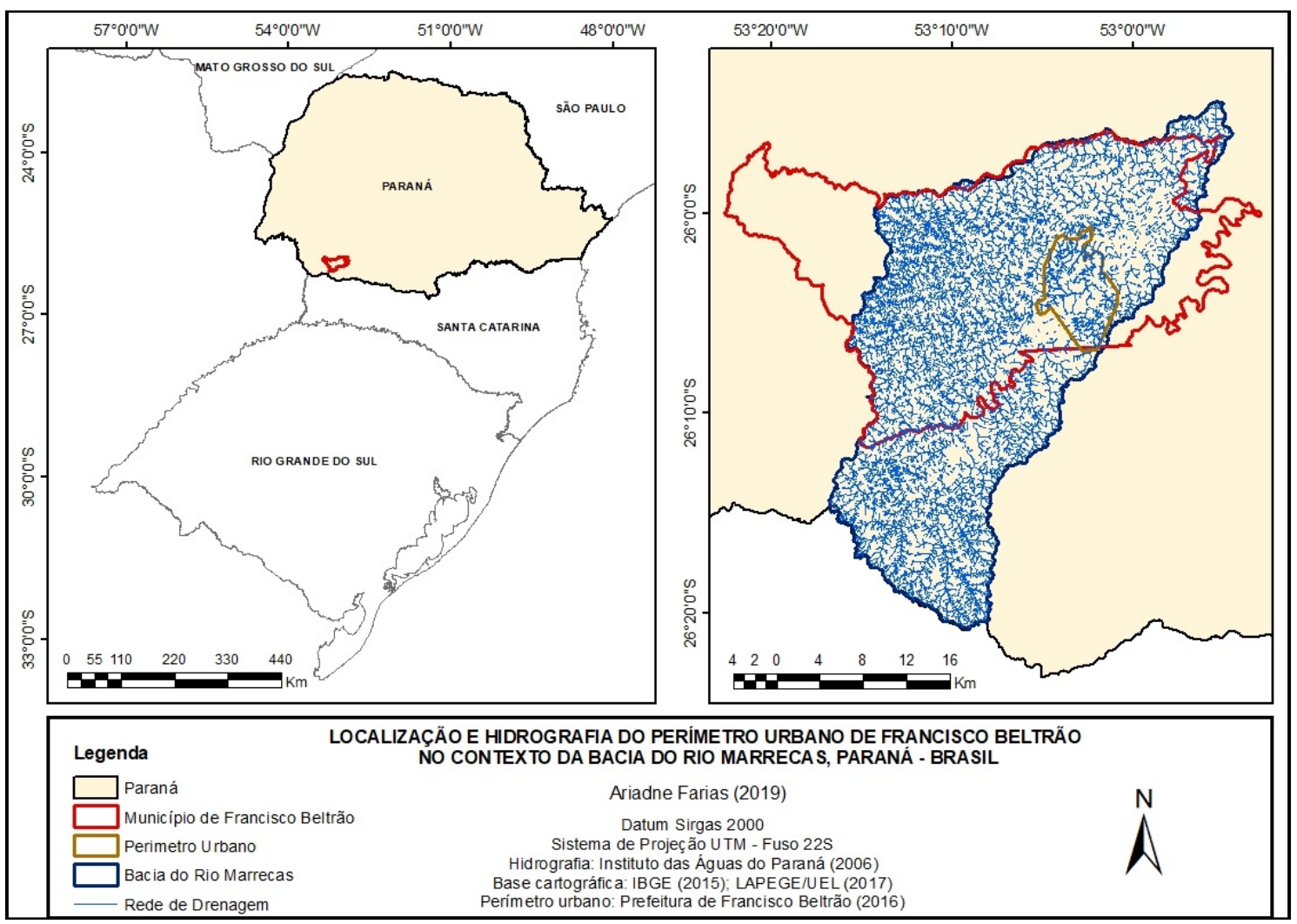

Figura 1: Francisco Beltrão / Brasil - mapa de localização do município e da hidrografia do perímetro urbano.

Fonte: Farias, 2019.

O estudo gerou uma representação espacial do perigo natural de inundação, com base na hidrodinâmica local e nas características morfométricas da bacia do rio Marrecas, para períodos de retorno dos eventos extremos de precipitação de 2, 5, 10 , 20, 50 e 100 anos. O mapeamento proposto teve por objetivo identificar as áreas atingidas pelas inundações, por meio das metodologias selecionadas para a modelagem hidrológica em interface com os Sistemas de Informação Geográfica (SIGs). Os softwares utilizados para a geração da modelagem hidrológica (HEC-HMS) e hidrodinâmica (HEC-RAS) constituem a metodologia adotada para identificar as áreas de perigo de inundação no perímetro urbano.

Neste trabalho, foi utilizado o ambiente SIG do ArcGIS (Environmental Systems Research Institute - ESRI) para a criação dos mapas, compilação dos dados geográficos e para a análise das informações mapeadas. Com o auxílio do SIG, o Modelo Digital de Elevação (MDE) da área de estudo também foi aplicado na identificação das cotas de inundação correspondentes aos períodos de retorno, indicados para a obtenção do modelo hidrológico. 
Como resultado, são apresentados dois produtos cartográficos: o mapa de perigo de inundação e o mapa das cotas de inundação urbana de Francisco Beltrão. Instrumentos de fundamental importância para os gestores públicos nas ações de planejamento urbano, os mapas também podem contribuir de forma efetiva para implantação de sistemas de monitoramento e de alerta dos órgãos brasileiros engajados na gestão dos riscos de desastres, como é o caso das secretarias de Proteção e Defesa Civil municipal (de Francisco Beltrão) e estadual (do Paraná).

\section{Modelagem hidrológica e mapeamento das áreas de perigo de inundação urbana}

As várzeas dos rios são áreas que, por serem consideradas unidades morfológicas com o próprio curso d'água, são naturalmente passíveis de alagamento periódico e sazonal. Elas fazem parte da hidrodinâmica local, isto é, do espaço onde o rio se movimenta. Portanto, o leito, a calha do rio e suas planícies de inundação constituem uma unidade morfológica fluvial (Spirn, 1995). Eventuais ocupações ao longo dessas áreas normalmente potencializam o espraiamento das águas; a impermeabilização de solo acarretada pela ocupação humana, quando no momento das enchentes e inundações, produz conflito entre as áreas territorialmente ocupadas pelas edificações e o movimento do nível das águas, ilustrado na Figura 2.

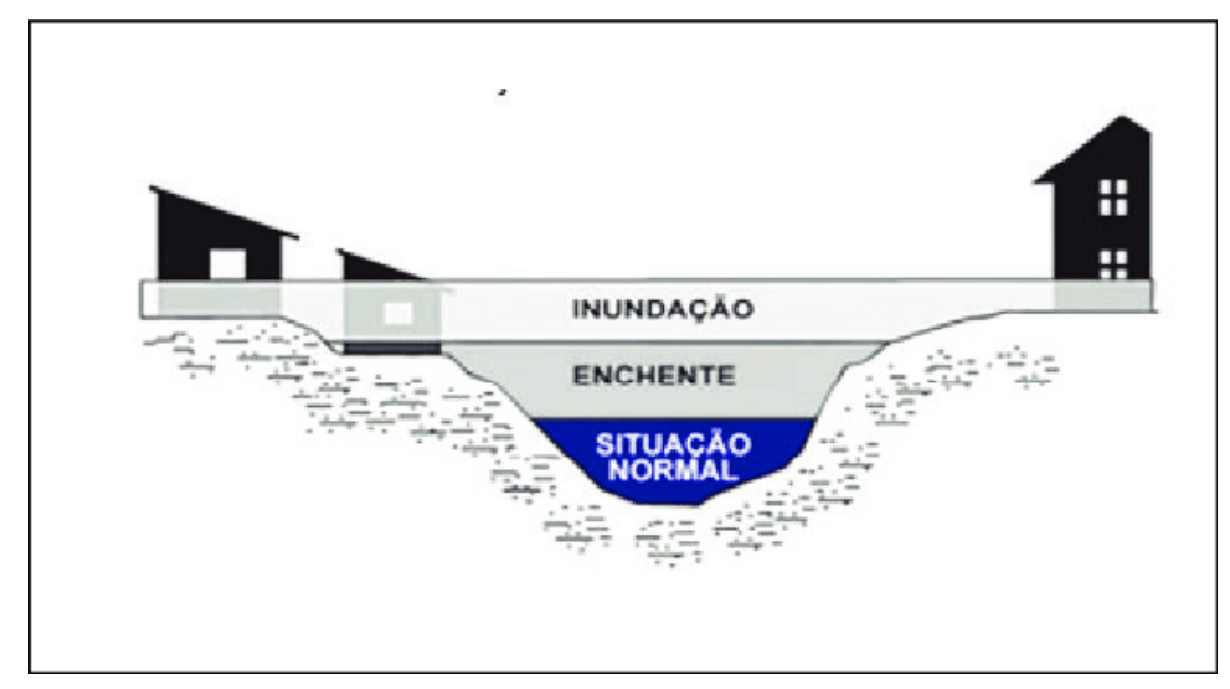

Figura 2: Perfil esquemático dos processos de enchente e inundação.

Fonte: Brasil, 2007.

As inundações ocorrem, principalmente, pelo processo natural no qual o rio ocupa o seu leito maior, de acordo com os eventos chuvosos extremos; a enchente ou cheia do rio pode ocorrer devido ao aumento gradual ou repentino da vazão, em decorrência de processo natural do ciclo hidrológico ou de alterações feitas na bacia hidrográfica (Tucci, 2007; 2005).

Em condições naturais, os rios ocupam dois leitos: o leito menor, seção de escoamento ou calha onde a água escoa na maior parte do tempo; e, o leito maior que é inundado em média a cada dois anos. Os problemas provenientes das 
enchentes ocorrem quando a população ocupa o leito maior do rio e, consequentemente, fica exposta ao perigo natural de inundação.

No Brasil, dependendo dos profissionais e instituições, traduz-se o termo em inglês hazard como "perigo" ou "ameaça". Em alguns casos observados na literatura, os termos perigo (hazard) e risco (risk) são comumente mencionados como sinônimos. No entanto, eles não são. A terminologia adotada pela United Nations International Strategy for Disasters Reduction (UNISDR, p. 17) define hazards como "a process, phenomenon or human activity that may cause loss of life, injury or other health impacts, property damage, social and economic disruption or environmental degradation". Enquanto o conceito do risco refere-se à "combination of the probability of an event and its negative consequences" (UNISDR, p. 25).

A definição adotada em Sendai e pela UNISDR (2015) demonstra que o risco é resultado de três componentes fundamentais: a) hazard, que traduz a probabilidade de ocorrência de um processo potencialmente danoso com uma determinada intensidade ou magnitude; b) exposição, que corresponde ao conjunto de valores (pessoas, bens econômicos ou patrimoniais, natureza, entre outros) sujeitos ou expostos ao impacto do hazard; c) vulnerabilidade, que traduz o grau de dano (físico, tangível ou intangível) ou de perdas econômicas, diretas ou indiretas.

Aneas de Castro (2000) utiliza peligros naturales como tradução para natural hazards. A autora explica que, no caso do risco, "el concepto incluye la probabilidad de ocurrencia de un acontecimiento natural o antrópico y la valoración por parte del hombre en cuanto a sus efectos nocivos (vulnerabilidad)", havendo tanto valoração quantitativa quanto qualitativa, estando a incerteza presente nas questões referentes ao risco. Quanto ao perigo natural, ela afirma que "en las investigaciones realizadas en geografía de los riesgos, se ha puesto cada vez más de manifiesto que peligro es un evento capaz de causar pérdidas de gravedad en donde se produzca" (Aneas de Castro, 2000, p. 2-3).

A autora defende a ideia de que o perigo implica na existência do homem que valora o que é um dano e o que não é. "Los fenómenos naturales no son en sí mismos perjudiciales, por ejemplo, para los antiguos egipcios las inundaciones del Nilo no eran acontecimentos peligrosos" (Aneas de Castro, 2000, p. 3). Sob essa perspectiva, inundações, tempestades severas, tornados, escassez hídrica, entre outros eventos adversos do clima, são fenômenos naturais que só se convertem em perigos quando se manifestam em regiões habitadas pelos seres humanos.

O conceito de perigo natural, portanto, refere-se ao fenômeno que ocorrem em determinados períodos e localidade conhecida, com potencial de causar sérios danos à população que vive nas áreas afetadas. Perigos naturais (natural hazards) são processos ou fenômenos naturais que se incidem sobre a biosfera, podendo constituir um evento danoso e serem modificados pela atividade humana, tais como a degradação do ambiente e urbanização. Enquanto o risco consiste na probabilidade de perda esperada para uma área habitada em um determinado tempo, devido à presença iminente de um perigo que pode ter origem natural ou, em outros casos, 
antrópica (Kobiyama et al., 2006, p.16; United Nations Development Programme UNDP, 2004).

Tratados os aspectos conceituais - ainda que de forma bastante sucinta - volta-se ao objetivo deste artigo e à ênfase acerca dos procedimentos metodológicos. Para fazer a avaliação dos riscos de inundação de um determinado local é necessário conhecer os processos hidrológicos, que são a fonte dos dados para a delimitação das áreas de perigo natural, ou seja, os espaços que serão atingidos pelo espraiamento das águas. A caracterização do comportamento hidrodinâmico é o primeiro procedimento a ser feito quando se pretende avaliar os riscos socioambientais de inundação, ao combinar o fator perigo natural com a vulnerabilidade social (Farias, 2019; Goerl, 2010).

O perigo natural de inundação pode ser espacialmente representado por meio da cartografia digital, de modo que representar o fenômeno em um mapa equivale a identificar e afirmar a presença do perigo iminente no espaço em questão. Dessa maneira, a cartografia e o zoneamento das áreas em que o perigo se manifesta constituem a base de uma política de prevenção de riscos de inundação. "A cartografia permite, ao mesmo tempo, a objetivação do risco e sua designação como problema público", enquanto o zoneamento "define os espaços em que há risco elevado, em que a ocupação deve ser regulamentada (às vezes proibida), e outros em que o risco é menor ou mesmo está ausente" (Veyret, 2007, p. 60).

O uso de Sistemas de Informação Geográfica (SIGs) e das ferramentas de geoprocessamento tem integrado o procedimento de entrada de alguns modelos hidrológicos. O SIG é uma tecnologia desenvolvida para o tratamento das informações espaciais e tem muitas aplicações ambientais, sociais e econômicas. Ao combinar informações topográficas, climáticas, tipo e uso do solo para pequenas áreas de uma bacia hidrográfica, o SIG permite a visualização de cenários passados, atuais, e a simulação de cenários futuros.

Integrados a essa tecnologia, os modelos hidrológicos são ferramentas bastante úteis para simular eventos passados e futuros e criar cenários que possibilitam gerenciar os riscos de inundação de uma determinada bacia hidrográfica, dentre outras aplicações. Segundo Rennó e Soares (2003, p.1), "um modelo hidrológico pode ser definido como uma representação matemática do fluxo de água e seus constituintes sobre alguma parte da superfície e/ou subsuperfície terrestre".

Tucci (2005) apresenta três classificações para os modelos hidrológicos: os modelos distribuídos, baseados em processos físicos; os modelos concentrados, com menor embasamento físico; e, o modelo de entrada-saída, com base nos dados de entrada (precipitação) e saída (vazão). No caso dos modelos distribuídos em processos físicos, são consideradas as equações de conservação da massa e quantidade de movimento para descrever o movimento da água sobre a superfície do solo. O cálculo é feito para cada célula da malha que representa a bacia. 
Os modelos distribuídos, agregados aos Modelos Digitais de Elevação (MDE) e ao geoprocessamento, têm buscado melhorar a representatividade espacial e temporal do comportamento das diferentes partes das bacias hidrográficas, sujeitas a diferentes ações antrópicas (Tucci, 2005). O mosaico do relevo, obtido através das técnicas de geoprocessamento, é base fundamental para a modelagem de sistemas hidrológicos.

O uso de SIG e das ferramentas de geoprocessamento tem integrado o procedimento de entrada de alguns modelos, uma vez que a caracterização dos aspectos naturais e do uso do solo gera uma grande quantidade de informações a serem processadas e transferidas para os modelos. Tal metodologia tem sido aplicada, principalmente, no caso dos modelos distribuídos, onde são estabelecidas relações entre características físicas e os parâmetros adotados na modelagem (Tucci, 2005).

\section{Procedimentos Metodológicos}

O ambiente SIG do ArcGIS foi selecionado para a criação e utilização dos mapas, compilação de dados geográficos e para a análise das informações mapeadas. Os softwares utilizados para a geração da modelagem hidrológica (HEC-HMS) e hidrodinâmica (HEC-RAS) constituem a metodologia adotada para identificar as áreas de perigo de inundação no perímetro urbano, conforme será detalhado.

Por meio da aplicação das técnicas e ferramentas do ArcMap 10.3 foi gerado o Modelo Digital de Elevação (MDE) da área de estudo, utilizando-se a base cartográfica do perímetro urbano, disponibilizada pela Prefeitura Municipal de Francisco Beltrão ao Laboratório de Geoprocessamento da Universidade Estadual do Oeste do Paraná. A carta topográfica gerada em 1980, quando foi realizado o levantamento aerofotogramétrico, apresenta curvas de nível com equidistância de $1 \mathrm{~m}$ e escala de 1:2000, atendendo aos parâmetros de entrada para o geoprocessamento das informações e para a simulação hidrológica e hidráulica do rio Marrecas.

A geração do modelo digital do terreno foi o primeiro procedimento para a geração do modelo hidrológico do perímetro urbano de Francisco Beltrão. Em seguida, deu-se início ao estudo hidrológico da bacia do rio Marrecas à montante da área de estudo, resumido na sequência metodológica de cinco passos indicados: 1) levantamento e análise dos dados pluviométricos da bacia hidrográfica; 2) determinação da chuva de projeto e cálculo da vazão de projeto; 3) delimitação das sub-bacias hidrográficas de contribuição; 4) cálculo das características físicas e parâmetros das sub-bacias de contribuição; e, 5) definição do tempo de concentração das sub-bacias de contribuição.

$\mathrm{Na}$ pesquisa em questão foi adotado o modelo distribuído por sub-bacias, que possibilitou a caracterização da bacia hidrográfica do rio Marrecas por meio da subdivisão dos sistemas hídricos localizados a montante da cidade, de acordo com hierarquia de drenagem, ou seja, o rio principal. Na modelagem hidrológica foram considerados os aspectos físico-ambientais de sete sub-bacias do rio Marrecas: a geomorfologia, a topografia e a rede de drenagem. 
O modelo hidrológico empregado foi o HEC-HMS, versão 3.5, desenvolvido pelo Hydrologic Engineering Center, do Corpo de Engenheiros do Exército dos EUA (US Army Corps of Engineers). O HEC-HMS contempla uma solução multimodelo, composta por diferentes alternativas de modelagem da precipitação de projeto, da precipitação efetiva, da concentração dos escoamentos por modelagem do escoamento superficial e da propagação de hidrogramas de cheia em cursos d'água, reservatórios e outras áreas de armazenamento.

Trata-se de um modelo semi-distribuído de simulação por evento. No caso do estudo hidrológico da bacia do rio Marrecas, empregaram-se as seguintes soluções de modelagem: chuvas efetivas calculadas por meio do método Soil Conservation Service (método SCS), com emprego do parâmetro CN (Curve Number); e, modelagem da concentração de escoamentos adotando-se o modelo do hidrograma unitário sintético triangular igualmente proposto pelo SCS.

A quantificação da chuva efetiva, parcela da precipitação que dá origem ao escoamento superficial, e a síntese do hidrograma de vazões podem ser obtidas pela metodologia proposta pelo Natural Resources Conservation Service - NSCR, anteriormente conhecido como SCS, órgão da administração pública federal dos EUA. A produção do modelo hidrológico requer a calibração de um parâmetro, denominado $\mathrm{CN}$, associado ao tipo e ao uso do solo, bem como ao estado inicial de umidade do solo (Pruski, Brandão \& Silva, 2004; Tucci, 2009).

Dessa maneira, os procedimentos do método SCS foram adotados para converter o quantil de chuva efetiva em vazão, considerando os aspectos físico-ambientais das sub-bacias hidrográficas que compõem a rede de drenagem da área de estudo. Também foram definidas as metodologias adequadas e estabelecidos os parâmetros físicos descritos a seguir:

a) (CN) denota Número da Curva Índice, o qual depende do uso e ocupação do solo no terreno da bacia de contribuição e representa um parâmetro do método utilizado para a transformação dos hietogramas totais em efetivos.

b) (la) denota a abstração inicial ocorrida no terreno da bacia de contribuição, calculada por meio do $(\mathrm{CN})$ e também utilizada na transformação dos hietogramas totais em efetivos.

c) $\left(t_{c}\right)$ denota o tempo de concentração da bacia; determinado através da metodologia proposta por G.B Williams.

d) (lagtime) também conhecido como tempo de retardo, ou intervalo de tempo existente do centro de massa dos hietogramas até a vazão de pico dos hidrogramas, que denota um parâmetro do método utilizado para a transformação chuva-vazão, equivalente a $60 \%$ (sessenta por cento) do tempo de concentração.

e) $(\Delta t)$ denota o intervalo de discretização dos hietogramas. 
A delimitação das principais sub-bacias, compostas pelos rios, córregos e arroios afluentes do rio Marrecas, foi feita a partir do delineamento das áreas de contribuição para a estimativa dos estudos hidrológicos (relação chuva-vazão) no perímetro urbano de Francisco Beltrão. Foram consideradas sete sub-bacias principais, apresentadas na Figura 3, cujos afluentes formam a bacia urbana da área de estudo.

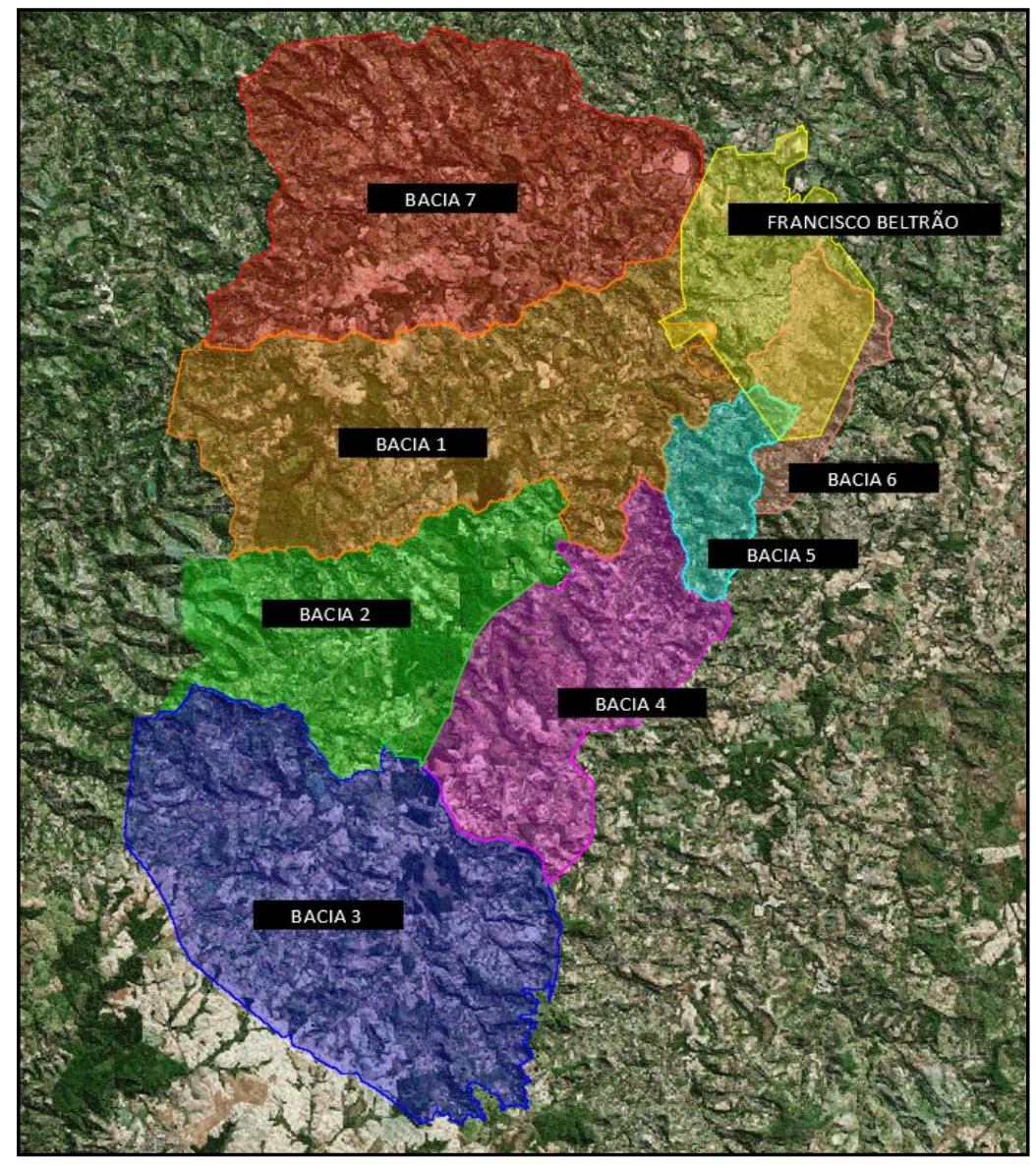

Figura 3: Francisco Beltrão / Brasil - sub-bacias contribuintes da bacia urbana. Fonte: Farias, 2019.

As sete sub-bacias, delimitadas na imagem acima, compõem a área de contribuição do volume de deflúvio da bacia urbana de Francisco Beltrão, e são drenadas pelos respectivos rios: 1) Rio Quatorze; 2) Rio Bonito; 3) Rios Verde e Araça; 4) Arroio Água Verde, rio Frio, Sanga dos Seres, arrorio Mandurira e córrego Escola; 5) Rio Lonqueador; 6) Rio Urutago e córrego São José; e, 7) Rios Erval e Santa Rosa. Os parâmetros morfométricos e o número da curva $(C N)$ das sub-bacias são apresentados na Tabela I e Tabela II. 
Tabela I: Parâmetros físicos e hidrológicos das sub-bacias do rio Marrecas.

\begin{tabular}{|c|c|c|c|c|}
\hline $\begin{array}{c}\text { SUB- } \\
\text { BACIA }\end{array}$ & $\begin{array}{c}\text { ÁREA DE } \\
\text { DRENAGEM } \\
\left.\mathbf{( k m}^{2}\right)\end{array}$ & $\begin{array}{c}\text { DECLIVIDADE } \\
\text { EQUIVALENTE } \\
\mathbf{( \% )}\end{array}$ & $\begin{array}{c}\text { TEMPO DE } \\
\text { CONCENTRAÇÃO } \\
(\mathbf{m i n})\end{array}$ & $\begin{array}{c}\text { LAG TIME } \\
\text { (min) }\end{array}$ \\
\hline 1 & 122.4 & $0.448 \%$ & 611.40 & 366.8 \\
\hline 2 & 72.9 & $0.810 \%$ & 224.02 & 134.4 \\
\hline 3 & 152.2 & $0.298 \%$ & 382.85 & 229.7 \\
\hline 4 & 62.3 & $1.239 \%$ & 219.21 & 131.5 \\
\hline 5 & 18.8 & $1.932 \%$ & 166.26 & 99.8 \\
\hline 6 & 24.3 & $0.212 \%$ & 414.24 & 248.5 \\
\hline 7 & 142.7 & $0.424 \%$ & 665.26 & 399.2 \\
\hline
\end{tabular}

Fonte: Farias, 2019.

De acordo com os estudos acerca das características do solo da bacia do rio Marrecas, a estrutura pedológica das sub-bacias pertence ao Grupo Hidrológico C, com condição de umidade antecedente II. Entre os solos descritos pelo método SCS, o Grupo tipo C é caracterizado por solos argilosos, apresentam taxas de infiltração menores e geram maior escoamento que os Grupos A e B. As condições de umidade antecedente do tipo II correspondem a estados intermediários entre solo seco (condição I), e saturado (condição III).

Tabela II: Francisco Beltrão - determinação do cn das sub-bacias do rio Marrecas

\begin{tabular}{|c|c|c|c|c|}
\hline $\begin{array}{c}\text { USO E OCUPAÇÃO } \\
\text { DO SOLO }\end{array}$ & MATA & CAMPO & \multirow{2}{*}{ SOLO } & \multirow{2}{*}{ CN PONDERADO } \\
\cline { 1 - 3 } $\mathbf{C N}$ & $\mathbf{6 0}$ & $\mathbf{6 0}$ & $\mathbf{6 6}$ & \multicolumn{1}{c}{} \\
\cline { 1 - 3 } Bacia & Área (\%) & Área (\%) & Área (\%) & \multirow{2}{*}{60.4} \\
\hline $\mathbf{1}$ & $37.6 \%$ & $52.0 \%$ & $6.3 \%$ & 60.3 \\
\hline $\mathbf{2}$ & $42.8 \%$ & $52.0 \%$ & $5.2 \%$ & 60.6 \\
\hline $\mathbf{3}$ & $23.0 \%$ & $67.1 \%$ & $9.9 \%$ & 60.3 \\
\hline $\mathbf{4}$ & $26.4 \%$ & $68.5 \%$ & $5.1 \%$ & 60.5 \\
\hline $\mathbf{5}$ & $36.5 \%$ & $55.3 \%$ & $8.1 \%$ & 65.0 \\
\hline $\mathbf{6}$ & $17.3 \%$ & $59.4 \%$ & $4.2 \%$ & 61.0 \\
\hline $\mathbf{7}$ & $22.2 \%$ & $72.2 \%$ & $2.4 \%$ & \\
\hline
\end{tabular}

Fonte: Farias, 2019.

Neste estudo de caso, optou-se pelo recorte espacial simplificado para facilitar a determinação do número de parâmetros para a construção do modelo hidrológico. A caracterização e análise simplificadas foram necessárias em função dos dados disponíveis da rede de drenagem e do curto espaço de tempo para a realização completa dos estudos. Todavia, o procedimento adotado não altera a qualidade dos resultados obtidos, uma vez que as características fisiográficas regionais das subbacias foram conservadas. 
Os parâmetros e as estimativas obtidas por meio do levantamento dos dados pluviométricos e determinação das vazões de projeto, além da delimitação das subbacias e a quantificação do escoamento superficial, constituíram os dados de entrada necessários para as simulações hidrológicas utilizando o software HEC-HMS (versão 3.5), desenvolvido pelo Hydrologic Engineering Center (HEC-USACE), do Corpo de Engenheiros do Exército dos Estados Unidos.

Para a simulação da propagação de cheias, proveniente da precipitação nas bacias de contribuição, utilizou-se o software HEC-RAS (River Analysis System), versão 5.03, também desenvolvido pelo HEC-USACE, pelo qual é possível obter cálculos de progressão bidimensional do escoamento. Esse software é capaz de determinar as elevações de nível de água e descarga em locais específicos ao longo de um curso de água, baseado na solução das equações de Saint-Venant - método numérico capaz de representar o comportamento do escoamento não permanente de um fluido.

Os softwares criados pelo HEC-USACE são amplamente utilizados em estudos de inundação. No estudo realizado em Francisco Beltrão foram simulados eventos de precipitação para os tempos de retorno (Tr) de 2, 5, 10, 20, 50 e 100 anos, com base nas metodologias indicadas em alguns estudos de caso feitos em cidades brasileiras, para as áreas de risco de inundação em bacias urbanas (Almeida, 2010; Goerl, 2010).

\section{Resultados obtidos}

Foram realizadas três simulações na tentativa de uma aproximação com o real, ou seja, considerando a modelagem hidrológica e a estimativa das vazões máximas para diferentes tempos de retorno. Os registros históricos das cheias e as observações em campo durante os eventos extremos, extravasamento dos rios, córregos e canais urbanos de Francisco Beltrão, permitem a verificação das áreas afetadas. A espacialização e a delimitação das manchas geradas pela inundação foram geradas pela metodologia de modelagem hidrológica e hidráulica, com o uso dos softwares HEC-HMS versão 3.5 e HEC-RAS versão 5.03, respectivamente.

Concluídas as simulações hidrológicas, selecionou-se o evento de duração crítica a ser utilizado no desenvolvimento do projeto, ou seja, o evento que resultou na maior vazão defluente ao perímetro urbano de Francisco Beltrão. Para o trabalho em questão o evento de duração crítica foi a precipitação com duração de dois (2) dias. $\mathrm{Na}$ simulação de inundação foram considerados cinco (5) pontos de entrada de hidrogramas na periferia do perímetro urbano. A Tabela III apresenta as vazões de pico de cada hidrograma considerado no estudo de cheias, vale ressaltar que as vazões presentes na tabela abaixo são os valores máximos do hidrograma resultante das simulações hidrológicas. 
Tabela III: Vazões de pico para cada tempo de retorno simulado.

\begin{tabular}{|c|c|c|c|}
\hline $\begin{array}{c}\text { TR } \\
\text { (ANOS) }\end{array}$ & CURSO D'ÁGUA & $\mathbf{Q}\left(\mathbf{M}^{3} / \mathbf{S}\right)$ & DURAÇÃO CRÍTICA \\
\hline \multirow{5}{*}{2} & Confluência do rio Quatorze e rio Marrecas & 220.89 & 2 dias \\
\hline & Rio Lonqueador & 11.77 & 2 dias \\
\hline & Córrego Urutago & 7.84 & 2 dias \\
\hline & Rio Santa Rosa & 87.32 & 2 dias \\
\hline & Córrego Progresso & 3.97 & 2 dias \\
\hline \multirow{5}{*}{5} & Confluência do rio Quatorze e rio Marrecas & 364.91 & 2 dias \\
\hline & Rio Lonqueador & 18.47 & 2 dias \\
\hline & Córrego Urutago & 12.31 & 2 dias \\
\hline & Rio Santa Rosa & 142.78 & 2 dias \\
\hline & Córrego Progresso & 5.82 & 2 dias \\
\hline \multirow{5}{*}{10} & Confluência do rio Quatorze e rio Marrecas & 469.04 & 2 dias \\
\hline & Rio Lonqueador & 23.16 & 2 dias \\
\hline & Córrego Urutago & 15.44 & 2 dias \\
\hline & Rio Santa Rosa & 182.44 & 2 dias \\
\hline & Córrego Progresso & 7.04 & 2 dias \\
\hline \multirow{5}{*}{20} & Confluência do rio Quatorze e rio Marrecas & 573.52 & 2 dias \\
\hline & Rio Lonqueador & 27.78 & 2 dias \\
\hline & Córrego Urutago & 18.52 & 2 dias \\
\hline & Rio Santa Rosa & 222.03 & 2 dias \\
\hline & Córrego Progresso & 8.22 & 2 dias \\
\hline \multirow{5}{*}{50} & Confluência do rio Quatorze e rio Marrecas & 713.72 & 2 dias \\
\hline & Rio Lonqueador & 33.89 & 2 dias \\
\hline & Córrego Urutago & 22.59 & 2 dias \\
\hline & Rio Santa Rosa & 274.98 & 2 dias \\
\hline & Córrego Progresso & 9.74 & 2 dias \\
\hline \multirow{5}{*}{100} & Confluência do rio Quatorze e rio Marrecas & 821.59 & 2 dias \\
\hline & Rio Lonqueador & 38.54 & 2 dias \\
\hline & Córrego Urutago & 25.69 & 2 dias \\
\hline & Rio Santa Rosa & 315.61 & 2 dias \\
\hline & Córrego Progresso & 10.88 & 2 dias \\
\hline
\end{tabular}

Fonte: Farias, 2019.

Em seguida, obteve-se a estimativa dos tempos de retorno das precipitações máximas, utilizados na determinação das vazões de projeto para a modelagem hidrológica, conforme demonstrado no Gráfico 1. 
Gráfico 1: Francisco Beltrão - tempo de retorno das precipitações máximas.



Fonte: Farias, 2019.

No caso do mapeamento proposto, foram utilizadas ferramentas de geoprocessamento que possuem interface com o modelo hidrológico semi-distribuído. Os resultados das modelagens hidrológica e hidráulica são interpretados por essas ferramentas que geram os mapas de cenários georreferenciados, ajustados posteriormente à imagem de satélite da área urbana de Francisco Beltrão. Nessa etapa do trabalho foi utilizado o Software ArcGIS 10.3, para produzir o mapa das áreas de perigo de inundação urbana apresentado na Figura 4, correspondentes aos períodos de retorno de 2, 5, 10, 20, 50 e 100 anos. 


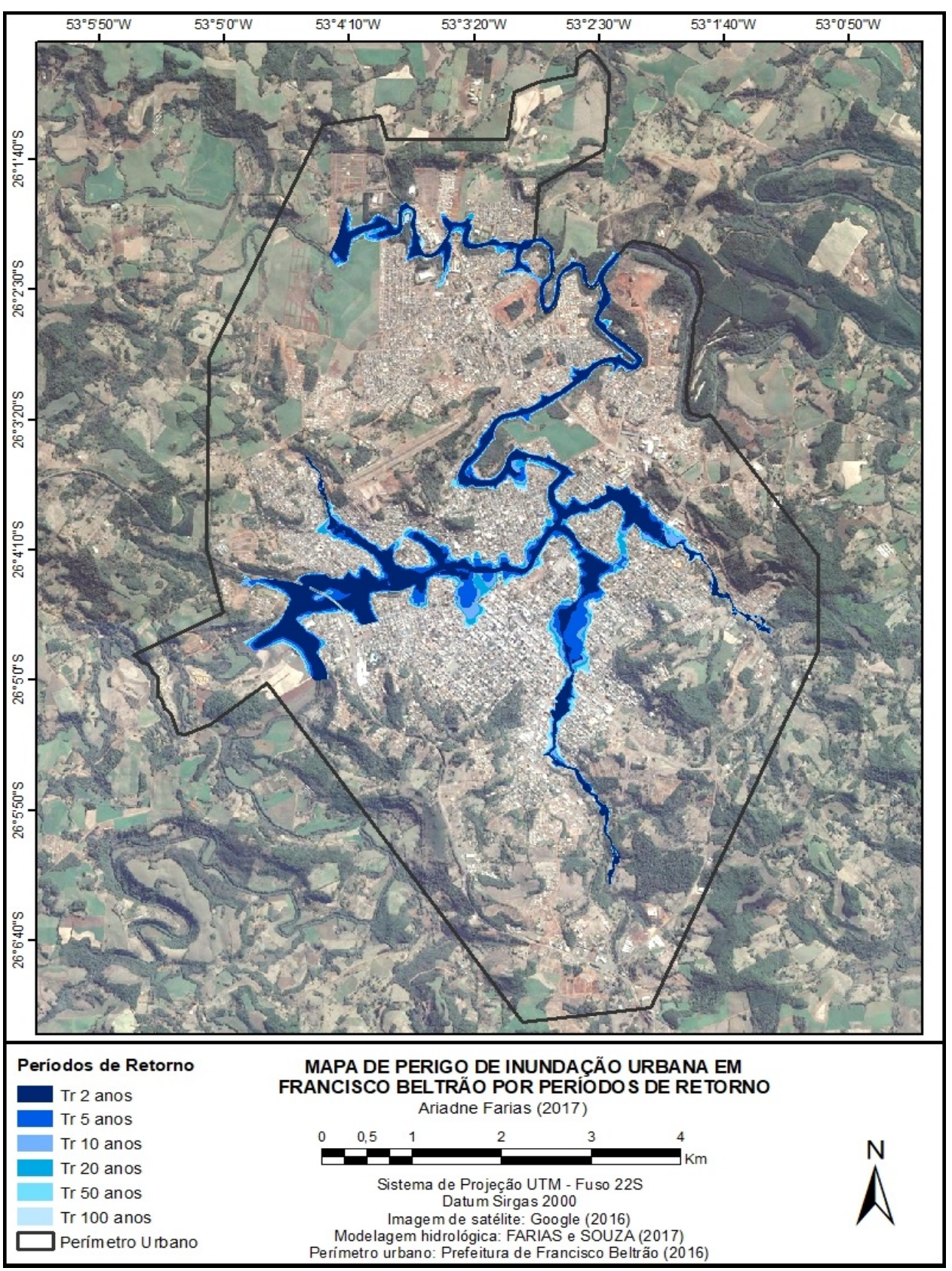

Figura 4: Francisco Beltrão / Brasil - áreas de perigo de inundação urbana. Fonte: Farias, 2017.

Na sequência, utilizou-se o MDE para gerar o mapa da Figura 5 que apresenta as cotas de inundação urbana correspondentes aos períodos de retorno. $\mathrm{O}$ principal objetivo é possibilitar uma leitura prática das informações que venha a ser utilizada como instrumento de aplicação às ações de planejamento urbano e às estratégias de monitoramento dos órgãos engajados na gestão do risco de desastres, como a Proteção e Defesa Civil municipal e estadual. 


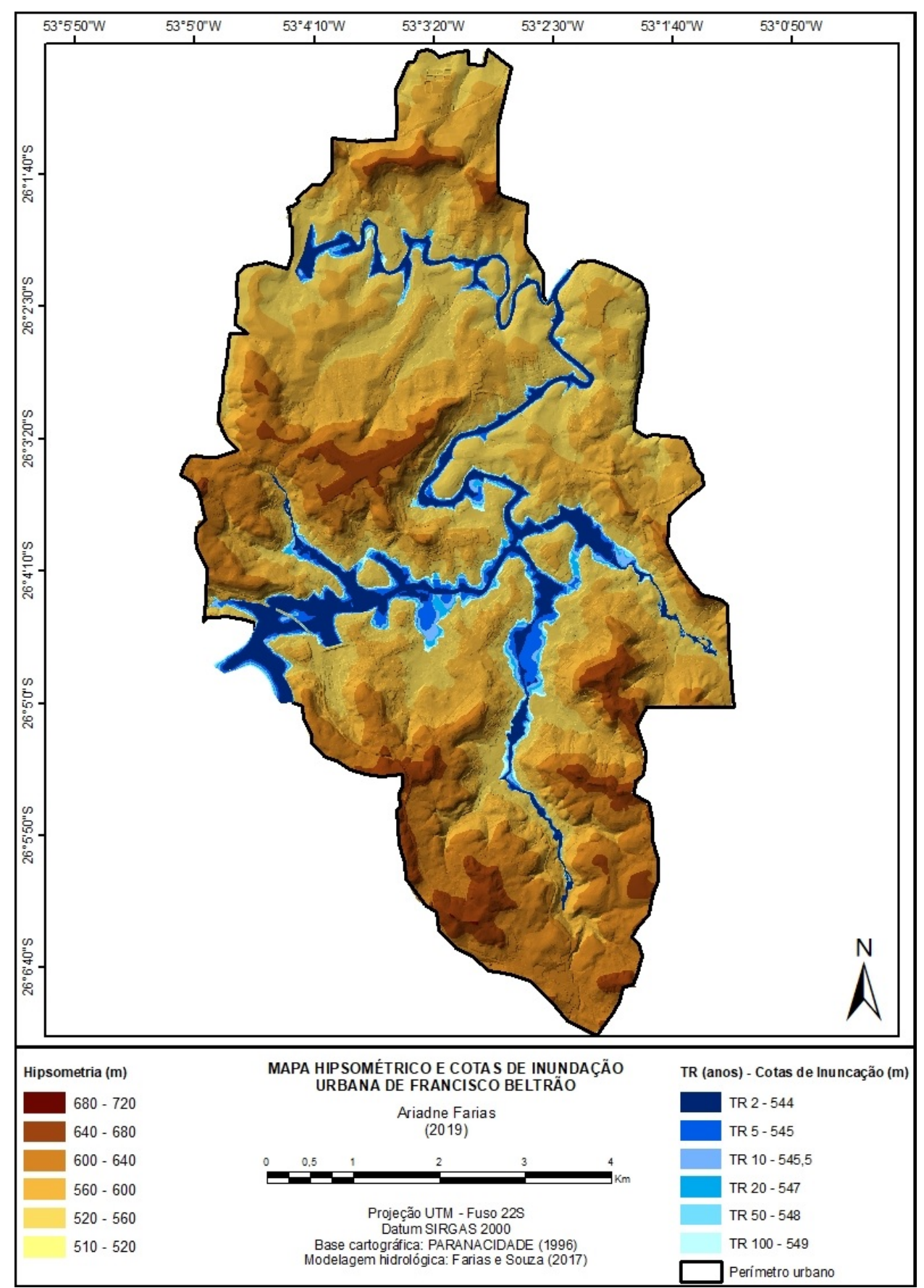

Figura 5: Francisco Beltrão / Brasil - hipsometria e cotas de inundação urbana.

Fonte: Farias, 2017.

Os resultados cartográficos demonstram que a modelagem hidrológica é uma técnica que possibilita o melhor entendimento e representação do comportamento hidrológico de bacias hidrográficas, sendo que os modelos hidrológicos possuem grande potencial para caracterizar a amplitude das ondas de cheia (enchentes) e localizar espacialmente a existência do perigo de inundação.

A aplicação do modelo hidrológico semi-distribuído para as sub-bacias que formam a rede de drenagem urbana de Francisco Beltrão permitiu a identificação das áreas de perigo de inundação. As informações espaciais produzidas podem ser utilizadas para 
a determinação do grau de risco socioambiental de cada área atingida pelas ondas de cheia e inundações dos canais, ao ser integrado às informações cartográficas da vulnerabilidade social para a mesma localidade.

Resumidamente, mas em consonância com os estudos propostos por Tucci (2005), a estrutura do modelo hidrológico construída para a realização desse trabalho consistiu nos seguintes elementos: discretização da bacia hidrográfica do rio Marrecas por meio das sub-bacias (modelo distribuído), variáveis de entrada (precipitação máxima), estrutura básica da integração dos processos (bacia e canal principal), aquisição de dados físicos da bacia e determinação dos parâmetros.

A caracterização dos aspectos físicos da bacia hidrográfica gera uma grande quantidade de informações a serem processadas e transferidas para os softwares utilizados para a construção dos cenários. Nesse caso, a qualidade do modelo do tipo distribuído é avaliada pela "capacidade em representar melhor a variabilidade espacial do sistema, sujeito às condições também variáveis da entrada, como a precipitação" (Tucci, 2005, p. 25). Enquanto que o grau de detalhamento do fenômeno representado está diretamente associado às informações disponíveis e à precisão desejada para representar a bacia.

A integração do SIG com os modelos hidrológicos e a sua aplicação em bacias hidrográficas permite a realização de um grande número de operações, como o projeto, calibração, simulação e comparação entre os modelos. O uso do SIG permite subdividir a bacia hidrográfica em subáreas homogêneas. No entanto, a maior limitação ao uso de modelos é a dificuldade em trabalhar grande quantidade de dados que descrevem a heterogeneidade dos sistemas naturais. Por essas razões, os SIG são empregados na criação do banco de dados dos modelos hidrológicos (Machado et al., 2003).

\section{Considerações Finais}

Importante instrumento para a gestão do risco de desastres, o mapa confere ao risco um caráter "objetivo", podendo ser estimado e definido de acordo com as especificidades e as problemáticas da área que se pretende mapear. Dessa forma, o trabalho cartográfico empregado na identificação das áreas de perigo natural de inundação vem se tornando um procedimento fundamental também nos processos de planejamento e gestão territorial, com destaque para a crescente demanda de estudos voltados ao espaço urbano, onde a aglomeração antrópica se tornou um fator de grande relevância.

A modelagem hidrológica empregada nesse trabalho possibilitou a identificação das áreas atingidas pelas inundações urbanas, para diferentes períodos de retorno dos eventos de precipitação máxima registrados na área de estudo. Isso garantiu uma informação espacial e graduada quanto ao nível das águas que uma determinada área apresenta, por meio da aplicação do mapeamento temático adequado. Tanto na esfera pública, como na iniciativa privada, a necessidade de uso das geotecnologias se mostra crescente, e o monitoramento contínuo das áreas depende da elaboração 
de modelos se aproximem da realidade dos fenômenos investigados, como o produto cartográfico apresentado neste artigo.

Ressalta-se que a utilização adequada dos modelos hidrológicos integrados à tecnologia dos SIG requer a construção de um banco de dados consistente e deve considerar uma série histórica de no mínimo 30 anos dos índices pluviométricos e das inundações ocorridas no local de estudo, além do zelo pela qualidade das bases cartográficas para a elaboração dos mapas (Tucci, 2009). No Brasil, observa-se que um dos problemas mais recorrentes que desafia os pesquisadores e os profissionais da área de gestão dos recursos hídricos é justamente a inconsistência dos dados disponibilizados pelas agências reguladoras.

Recomenda-se, portanto, que a seleção das metodologias e dos recursos tecnológicos seja feita de acordo com uma avaliação prévia da disponibilidade e confiabilidade dos dados necessários à modelagem, procedimento de fundamental importância para se obter resultados satisfatórios. Deve-se observar a periodicidade da série histórica da precipitação local e a consistência dos dados compilados que caracterizam a bacia hidrográfica para, então, fazer a seleção das metodologias e técnicas da cartografia digital que serão aplicadas.

No estudo de caso de Francisco Beltrão, foram diagnosticados alguns problemas técnicos na base topográfica e algumas lacunas no registro da série histórica das precipitações, que foram minimizados pela aplicação das técnicas de geoprocessamento e pelo tratamento dos dados pluviométricos. Portanto, é importante mencionar que a qualidade dos resultados obtidos por meio do modelo hidrológico ficou restrita à qualidade dos dados disponíveis para a realização do trabalho.

\section{Bibliografia}

Almeida, L. Q. de. (2010). Vulnerabilidades socioambientais de rios urbanos: bacia hidrográfica do rio Maranguapinho, região metropolitana de Fortaleza, Ceará. Tese (Doutorado em Geografia). Universidade Estadual Paulista, Instituto de Geociências e Ciências Exatas. Rio Claro.

Aneas de Castro, S. D. (2000). Riesgos y peligros: una visión desde lá Geografía. Scripta Nova: Revista Electrónica de Geografía y Ciencias Sociales, n. 60, 1-13. Consultado em 14 de setembro de 2019, em http://www.ub.edu/geocrit/sn-60.htm.

Brasil (2007). Mapeamento de riscos em encostas e margem de rios. Brasília: Ministério das Cidades: Instituto de Pesquisas Tecnológicas (IPT). Consultado em 14 de setembro de 2019, em http://bibspi.planejamento.gov.br/handle/iditem/185.

Farias, A. (2019). Inundações Urbanas em Francisco Beltrão/PR: riscos e vulnerabilidades socioambientais. Tese de Doutorado em Meio Ambiente e Desenvolvimento. Universidade Federal do Paraná.

Goerl, R. F. (2010). Estudo de Inundações em Rio Negrinho - SC sob a ótica dos desastres naturais. Dissertação de Mestrado em Geografia. Universidade Federal de Santa Catarina. 
Kobiyama, M., Mendonça, M., Moreno, D. A., Marcelino, I., Marcelino, E., Gonçalves, E. F., Brazetti, L. P., Goerl, R. F., Molleri, G. F., Rudorff, F. M. (2006). Prevenção de desastres naturais: conceitos básicos. Curitiba: Editora Organic Trading. Consultado em 15 de setembro de 2019, em http://logatti.edu.br/images/prevencaodesastres.pdf.

Kobiyama, M., Checchia, T., Silva, R. V., Schroder, P. H., Grando, A., Reginatto, G. M. P. (2004). Papel da comunidade e da universidade no gerenciamento de desastres naturais. In: Simpósio Brasileiro de Desastres Naturais (p. 834-846). 1. Florianópolis: Grupo de Estudos de Desastres Naturais - GEDN/UFSC. Consultado em 15 de setembro de 2019, em http://www.labhidro.ufsc.br/Artigos/Sibraden2004\%205-65\%20(gestao).pdf.

Machado, R. E. vettorazzi, C. A. (2003). Simulação da produção de sedimentos para a microbacia hidrográfica do ribeirão dos Marins, SP. Revista Brasileira Ciência do Solo, n. 4, 735-741. Consultado em 14 de setembro de 2019, em http://www.scielo.br/pdf/rbcs/v27n4/a18v27n4.pdf.

Mendonça, F. (2004). S.A.U. Sistema Ambiental Urbano: uma abordagem dos problemas socioambientais da cidade. In: Mendonça, Francisco. (Org.). Impactos socioambientais urbanos (p. 209-218). Curitiba: UFPR.

Mendonça, F. (2004a). Riscos, vulnerabilidade e abordagens socioambiental urbana: uma reflexão a partir da RMC e de Curitiba. Revista Desenvolvimento e Meio Ambiente, Curitiba, n. $10,139-148$.

Monteiro, C. A. F. (1991). Clima e Excepcionalismo: conjecturas sobre o desempenho da atmosfera como fenômeno geográfico. Florianópolis: Editora da UFSC.

Pruski, F. F., Brandão, V. dos S., Silva, D. D. da. (2004). Escoamento Superficial. 2. ed. Viçosa: Universidade Federal de Viçosa.

Renné, C. D., Soares, J. V. (2003). Conceitos básicos de modelagem hidrológica. In: Câmara, G. Monteiro, A. M. V. Tutorial: introdução à modelagem dinâmica espacial. São José dos Campos: Instituto Nacional de Pesquisas Espaciais - INPE. Consultado em 15 de setembro de 2019, em http://www.clickgeo.com.br/livros-online-dpi-inpe/.

Spirn, A. W. (1995). O jardim de granito: a natureza no desenho da cidade. São Paulo: Editora da Universidade de São Paulo.

Tucci, C. E. M. (2009). Hidrologia: ciência e aplicação. Tucci, Carlos E. M., Bertoni, Juan C. (Org.). 4.ed. Porto Alegre: Editora da UFRGS/ABRH.

Tucci, C. E. M. (2007). Inundações urbanas. Porto Alegre: ABRH/RHAMA.

Tucci, C. E. M. (2005). Modelos hidrológicos. 2.ed. Porto Alegre: Editora da UFRGS.

Tucci, C. E. M. (2003). Inundações e Drenagem Urbana. Em: Tucci, Carlos E. M., Bertoni, Carlos (Org.). Inundações urbanas na América do Sul (p.45-150). Porto Alegre: Associação Brasileira de Recursos Hídricos.

United Nations International Strategy for Disaster Reduction - UNISDR (2015). Sendai Framework for Disaster Risk Reduction 2015-2030. Geneva: UNISDR. Consultado em 14 de setembro de 2019, em http://www.preventionweb.net/files/43291 sendaiframeworkfordrren.pdf. 
United Nations International Strategy for Disaster Reduction - UNISDR (2009). Terminology on Disaster Risk Reduction. Geneva: UNISDR. Consultado em 14 de setembro de 2019, em https://www.unisdr.org/files/7817 UNISDRTerminologyEnglish.pdf.

United Nations Development Programme - UNDP. (2004). Reducing disaster risk: a challenge for development. New York: UNDP.

Veyret, Y. (Org.) (2007). Os riscos: o homem como agressor e vítima do meio ambiente. São Paulo: Contexto.

Artigo recebido em / Received on: 29/07/2019

Artigo aceite para publicação em / Accepted for publication on: 22/10/2019 
Farias e Mendonça / Physis Terrae, Vol. 1, n 1, 2019, 73-91

Página intencionalmente deixada em branco 